\title{
Comparative Economic Analysis of Physical, Chemical, and Hybrid Absorption Processes for Carbon Capture
}

\author{
Xiang Zhang ${ }^{\mathrm{a}}$, Zhen Song ${ }^{\mathrm{b}}$, Rafiqul Gani ${ }^{\mathrm{c}}$, Teng Zhou ${ }^{\mathrm{b}, \mathrm{d},{ }^{*}}$ \\ ${ }^{a}$ Department of Chemical and Biological Engineering, The Hong Kong University of Science \\ and Technology, Clear Water Bay, Hong Kong, China \\ ${ }^{\mathrm{b}}$ Process Systems Engineering, Max Planck Institute for Dynamics of Complex Technical \\ Systems, Sandtorstr. 1, 39106 Magdeburg, Germany \\ ${ }^{c}$ PSE for SPEED Company Ltd., Skyttemosen 6, DK-3450 Allerod, Denmark \\ ${ }^{\mathrm{d}}$ Process Systems Engineering, Otto-von-Guericke University Magdeburg, Universitätsplatz 2, \\ 39106 Magdeburg, Germany \\ * Corresponding author: zhout@mpi-magdeburg.mpg.de (Teng Zhou)
}

\begin{abstract}
Due to the variability of $\mathrm{CO}_{2}$ emission sources, a proper selection of viable and cost-effective technology for carbon capture is highly critical. In this work, a comparative economic analysis of physical, chemical, and hybrid physical-chemical absorption processes is performed to guide the selection of appropriate carbon capture technologies for different types of $\mathrm{CO}_{2}$ sources. First, the three different absorption processes are designed and simulated for treating various industrial $\mathrm{CO}_{2}$-containing gases with distinct pressures and $\mathrm{CO}_{2}$ concentrations. Then, the total annualized costs of the processes are calculated and compared. It is found that for carbon capture at atmospheric pressure, chemical absorption exhibits the highest performance for low $\mathrm{CO}_{2}$ concentrations $\left(<30.4 \%\right.$ ), hybrid absorption is most economical for medium $\mathrm{CO}_{2}$ composition (30.4\% 59.3\%), and physical absorption is most cost-effective for high $\mathrm{CO}_{2}$ content (> 59.3\%). For treating high-pressure $\mathrm{CO}_{2}$-containing gases (e.g., pre-combustion carbon capture), the hybrid physical-chemical absorption process is economically preferred.
\end{abstract}

Keywords: $\mathrm{CO}_{2}$ capture, $\mathrm{CO}_{2}$ absorption, process simulation, economic analysis 


\section{Introduction}

In 2018, the global energy-related $\mathrm{CO}_{2}$ emissions reached a historically high level of 33.1 gigatonnes. ${ }^{1}$ Given the increasing demand for energy, $\mathrm{CO}_{2}$ emissions are expected to continuously rise in the future. It has been indicated that $\mathrm{CO}_{2}$ emissions contribute to global warming and cause the anthropogenic climate change. ${ }^{2,3}$ Therefore, effective decarbonization strategies are significant for mitigating the risk of global warming. Carbon capture, storage, and utilization (CCSU) has been regarded as an attractive route to reduce $\mathrm{CO}_{2}$ emissions. ${ }^{3-5}$ It involves the capture, compression, transportation, geological storage, and various utilizations of $\mathrm{CO}_{2}$. Among them, $\mathrm{CO}_{2}$ capture accounts for the majority of the total cost. ${ }^{6,7}$ In this regard, the development of viable and cost-effective carbon capture technologies is highly desired.

Among all the current carbon capture strategies, solvent-based absorption is most technologically mature and has been widely implemented in commercial scale for many years..$^{7-9}$ For chemical absorption, $\mathrm{CO}_{2}$-containing gases are usually treated with amine-based solvents, such as the monoethanolamine (MEA) solution. The solvent selectively reacts with $\mathrm{CO}_{2}$ to form water-soluble salts without absorbing other gases. ${ }^{10}$ For physical absorption, $\mathrm{CO}_{2}$ is physically absorbed in a solvent (usually under high pressure) while other gases remain in the gaseous phase due to their relatively small solubility. One of the most popular physical solvents is Dimethyl Ethers of Polyethylene Glycol (DEPG), which has already been commercially used in the Selexol ${ }^{\mathrm{TM}}$ process. $^{11}$ These two absorption technologies have their own strengths and weaknesses, and are suitable for different application situations. ${ }^{12-14}$ For instance, it has been reported that chemical absorption is preferred for treating diluted- $\mathrm{CO}_{2}$ gases while physical absorption favors high $\mathrm{CO}_{2}$ partial pressures. ${ }^{12}$ Globally, more than 8,000 large stationary $\mathrm{CO}_{2}$ 
emission sources exist covering many industrial sectors such as cement manufacturing, steel making, coal-fired power plant, etc. ${ }^{4}$ As listed in Table 1 , the $\mathrm{CO}_{2}$-containing gases in different sectors can have significant differences in their pressure and composition. For instance, the gas can be at atmospheric pressure or at high pressure up to 80 bar. For gases at atmospheric pressure, the $\mathrm{CO}_{2}$ molar fraction can range from $9 \%$ to $76 \%{ }^{15-18}$ Therefore, taking into account the variability of $\mathrm{CO}_{2}$ emission sources, a clear and quantitative guideline for the selection of suitable absorption processes is significant. ${ }^{15,19}$

In addition to physical and chemical absorption, the hybrid physical-chemical absorption process has also been proposed, which takes advantages of the single technologies and overcomes their individual inherent limitations. ${ }^{20,21}$ Generally, in this hybrid process, the bulk $\mathrm{CO}_{2}$ is first removed using physical absorption and the residual $\mathrm{CO}_{2}$ is separated by chemical absorption to meet the purity requirements. Despite this advantage, the hybrid process has its own weakness. It may lead to a high investment in building the physical and chemical absorption facilities. It has been indicated that depending on the feed gas conditions, the economic performance of the hybrid absorption process can be higher or lower than the single absorption processes. ${ }^{22}$ Therefore, a rigorous and quantitative analysis is necessary to decide when and how physical, chemical, and hybrid absorption processes should be adopted for specific carbon capture tasks. It should be mentioned that an optimal combination of different separation technologies, such as absorption, adsorption, and membrane separation, is also referred as a hybrid scheme. ${ }^{23}$ However, this is not studied in the present work.

This paper is organized as follows. First, the detailed modeling of three processes including DEPG-based physical absorption, MEA-based chemical absorption, and the hybrid physical and 
chemical absorption processes is presented. The process economic evaluation method is then introduced. Afterwards, two scenarios are defined based on the different pressures of industrial feed gases. In each scenario, the three processes are modeled and simulated in Aspen Plus. The total annual costs of the processes are calculated and compared, based on which quantitative guidelines for the optimal selection of most-efficient $\mathrm{CO}_{2}$ absorption technology are summarized.

\section{Process Simulation and Economic Evaluation}

Figure 1 depicts the flowsheets of three processes: DEPG-based physical absorption process (a), MEA-based chemical absorption process (b), and hybrid physical-chemical absorption process (c). In each process, a gas mixture with a certain $\mathrm{CO}_{2}$ concentration is fed as the input. The final goal is to capture no less than $90 \% \mathrm{CO}_{2}$ from the feed gas, as stated in Equation (1). The captured $\mathrm{CO}_{2}$ is compressed to 150 bar and cooled down to $25{ }^{\circ} \mathrm{C}$ for storage and/or later utilization. Note that the optimal transportation and storage of compressed $\mathrm{CO}_{2}$ or their later utilization are not considered here and have been studied elsewhere. ${ }^{24-26}$

$$
F^{s} \cdot x_{\mathrm{CO}_{2}}^{s} \geq 0.9 \cdot F^{f} \cdot x_{\mathrm{CO}_{2}}^{f}
$$

$F$ and $x$ denote molar flowrate and molar fraction, respectively. The superscripts $f$ and $s$ represent the feed gas and $\mathrm{CO}_{2}$ storage stream, respectively. Moreover, the cleaned gas should contain no more than $1 \% \mathrm{CO}_{2}$, as given by Equation (2). ${ }^{9}$

$$
x_{C O_{2}}^{c} \leq 0.01
$$

where the superscript $c$ denotes the clean gas. 


\subsection{DEPG-based Physical Absorption}

Figure 1a shows the DEPG-based physical absorption process (i.e., the 'Selexol' process). ${ }^{11,27,28}$ As depicted, the feed gas is first compressed by a two-stage compressor chain with inter-cooling since high pressure is favorable to physically dissolve $\mathrm{CO}_{2}$. The compressed gas is sent to an absorber where it is counter-currently contacted with the DEPG solvent. The specific composition of the DEPG mixture has been given by Zubeir et al. ${ }^{29}$ The clean gas is collected from the top while the $\mathrm{CO}_{2}$-loaded solvent leaves from the bottom of the absorber. Afterwards, the $\mathrm{CO}_{2}$-rich solvent enters the first flash drum which has a lower pressure than that of the absorber. Upon the pressure drop, most of the dissolved low-solubility gases $\left(\mathrm{N}_{2}, \mathrm{O}_{2}, \mathrm{CO}\right.$, $\mathrm{H}_{2}$ ) and a certain amount of $\mathrm{CO}_{2}$ are released from the solvent. These gases are re-compressed and recycled back to the absorber in order to reduce the loss of gas. Later, the solvent is regenerated in three flash drums with decreasing pressures and sent back to the absorber. The released $\mathrm{CO}_{2}$ is compressed and sent for storage and/or utilization. The compression process is carried out via a multi-stage compressor chain with inter-cooling.

\subsection{MEA-based Chemical Absorption}

Figure $1 \mathrm{~b}$ depicts the chemical absorption process whose simulation model is built according to the Aspen Plus guide manual. ${ }^{30}$ The feed gas is first cooled and sent into the absorber where the gas flows counter-currently against the MEA solvent, a $30 \mathrm{wt} \%$ MEA water solution. ${ }^{15}$ In the absorber, the $\mathrm{CO}_{2}$ in the feed gas dissolves into the solvent via chemical reactions. The involved reactions and the corresponding reaction equilibrium constants have been reported by Aboudheir et al. ${ }^{31}$ The clean gas leaves the top of the absorber while the bottom product, $\mathrm{CO}_{2}$-loaded MEA solvent, is heated and sent to a stripper for desorption in order to regenerate the solvent. Since a 
small amount of MEA solution is lost in the stripper, makeup solvent is added to the absorber. The stripped $\mathrm{CO}_{2}$ flows through a cooler and a flash drum to remove the water moisture. Afterwards, it is fed to a four-stage compressor chain with inter-cooling and finally discharged at 150 bar and $25^{\circ} \mathrm{C}$.

\subsection{Hybrid Physical-chemical Absorption}

The flowsheet of the hybrid absorption process is illustrated in Figure 1c. It consists of three subsystems, i.e., DEPG-based physical absorption, MEA-based chemical absorption, and threestage compressor chain with inter-cooling. ${ }^{20}$ The gas mixture is first fed into the physical absorption subsystem where the bulk of $\mathrm{CO}_{2}$ is captured. The $\mathrm{CO}_{2}$ molar fraction in the intermediate stream leaving the physical absorber, $x_{\mathrm{CO}_{2}}^{i}$, is a key parameter that should be optimally selected according to different feed gas conditions. Afterwards, the intermediate stream flows through a pressure-relief valve and then enters the chemical absorber to capture the residual $\mathrm{CO}_{2}$. The reason why a reduced pressure is used in chemical absorption is that a high pressure does not substantially enhance the absorption efficiency but results in a much larger capital cost. Since the $\mathrm{CO}_{2}$ collected from the chemical absorption subsystem and the gas flows out of the third flash drum $(\mathrm{F} 3 \mathrm{~h})$ has the same pressure, they are mixed together before further compression.

\subsection{Process Economic Evaluation}

After process design and simulation, the economic performance of the three absorption processes should be evaluated. In this work, process total annualized cost (TAC) is considered. As shown in Equation (3), TAC is the summation of annualized capital cost $(A C C)$ and operating 
cost $(A O C) . A C C$ is related to total capital cost $\left(C_{c a p}\right) . C R F$ is the capital recovery factor related to the discounted rate $(d r)$ and the life-time of equipment $(n) .{ }^{32} A O C$ depends on the annual utility cost $\left(C_{u t}\right)$. In addition, it is assumed that $\alpha \cdot C_{u t}$ accounts for the other operating costs including maintenance cost, labor cost, etc. The parameter $\alpha$ denotes the ratio of other operating costs over the utility cost.

$$
\begin{aligned}
& T A C=A C C+A O C \\
& A C C=C R F \cdot C_{c a p} \\
& C R F=\frac{d r \cdot(1+d r)^{n}}{(1+d r)^{n}-1} \\
& A O C=C_{u t}+\alpha \cdot C_{u t}
\end{aligned}
$$

\section{Results and Discussion}

The three absorption processes are simulated in Aspen Plus V9. The capital and utility costs are directly evaluated using Aspen Process Economic Analyzer. Key cost parameters, such as $d r, n, \alpha$ and steam, cooling water, and electricity prices, are listed in Table S1 (Supporting Information). According to the composition and pressure of various industrial $\mathrm{CO}_{2}$-containing gases (Table 1), several representative feed gases are selected and studied with their detailed conditions summarized in Table 2. As indicated, two scenarios are considered based on the pressure difference. For gases at atmospheric pressure (Scenario 1), six cases with $\mathrm{CO}_{2}$ molar contents of $15 \%$ (post-combustion flue gas), $25 \%, 35 \%$ and $45 \%$ (flue gas in iron and steel industries), 55\% and 65\% (oxy-combustion flue gas) are investigated. Scenario 2 considers high- 
pressure pre-combustion gas treatment. A pressure of 30 bar and $\mathrm{CO}_{2}$ concentration of $35 \%$ are selected according to the industrial reality. In both scenarios, the feed gas flowrate $F^{f}$ and temperature are set to $1 \mathrm{kmol} / \mathrm{s}$ and $40{ }^{\circ} \mathrm{C}$, respectively. Detailed settings in the process simulator including component specifications, thermodynamic and unit operation model selection, as well as the operating conditions of each unit are elaborated in Table S2-S6 (Supporting Information).

\subsection{Scenario 1: Gases at Atmospheric Pressure}

In this scenario, $\mathrm{CO}_{2}$-containing gases at atmospheric pressure are considered as the feed gas. Each of the six feed gases (Table 2) is treated with the three absorption processes (Figure 1). In order to fulfill the separation requirements given in Equations (1)-(2), the absorber pressure in the physical absorption process is adjusted for each feed gas condition. The flow rate of recycled MEA solvent in the chemical absorption process is identified in a similar way. For the hybrid absorption process, the $\mathrm{CO}_{2}$ molar fraction in the intermediate stream $x_{\mathrm{CO}_{2}}^{i}$ is a key parameter that can be changed by altering the operating pressure in the physical absorber. After preliminary calculations, it is known that to select a $\leq 5 \%$ value for $x_{\mathrm{CO}_{2}}^{i}$ is favorable for minimizing the $T A C$ of the hybrid process. Considering the final goal of reducing the $\mathrm{CO}_{2}$ content to $1 \%, x_{\mathrm{CO}_{2}}^{i}=$ $1.5 \%, 2 \%, 3 \%, 4 \%$ and $5 \%$ are selected to study the influence of $x_{\mathrm{CO}_{2}}^{i}$ on the process TAC. It is worth noting that the process simulation results indicate that except $\mathrm{CO}_{2}$, the other gases $\left(\mathrm{N}_{2}, \mathrm{O}_{2}\right.$, $\mathrm{CO}$ and $\mathrm{H}_{2}$ ) are almost insoluble in both physical and chemical solvents. Therefore, the TAC of the physical and chemical absorption processes only depends on the $\mathrm{CO}_{2}$ molar fraction in the feed gas $x_{\mathrm{CO}_{2}}^{f}$ and the TAC of the hybrid absorption process depends on both $x_{\mathrm{CO}_{2}}^{f}$ and $x_{\mathrm{CO}_{2}}^{i}$.

Table 3 summaries the obtained TAC of all the process alternatives for different $x_{\mathrm{CO}_{2}}^{f}$ and $x_{\mathrm{CO}_{2}}^{i}$. 


\subsubsection{Comparison between physical and chemical absorption}

Figure 2 shows the dependence of the TAC of the physical and chemical absorption processes on $x_{\mathrm{CO}_{2}}^{f}$. It is found that chemical absorption is more economically preferred when the feed $\mathrm{CO}_{2}$ molar fraction is less than $32 \%$. Otherwise, the physical absorption process results in a lower cost. In order to better understand the process TAC, Figure 3 shows the cost breakdown of the two processes for three types of feed gases with 15\% (low-level), 35\% (medium-level), and 65\% (high-level) $\mathrm{CO}_{2}$. As indicated, electricity cost dominates the TAC of physical absorption. The large amount of electricity is consumed for compressing the feed gas and captured $\mathrm{CO}_{2}$. Moreover, the electricity expense increases slightly with $x_{\mathrm{CO}_{2}}^{f}$. In terms of chemical absorption, the majority of the TAC originates from the cost of steam that is used to regenerate the MEA solvent. The required amount of steam increases linearly with the $\mathrm{CO}_{2}$ content, which results in a significant $T A C$ expansion.

\subsubsection{Comparison between single and hybrid absorption}

In order to identify when hybrid absorption is more cost-effective and how to select the intermediate $\mathrm{CO}_{2}$ molar fraction $x_{\mathrm{CO}_{2}}^{i}$ in the hybrid process, the $T A C$ of the three absorption processes are compared. As indicated in Figure $4 \mathrm{a}$, when the feed gas contains $15 \% \mathrm{CO}_{2}$, the cost of the hybrid absorption process decreases as $x_{\mathrm{CO}_{2}}^{i}$ increases from $1.5 \%$ to $5 \%$. More importantly, the TAC of the hybrid process is higher than that of the chemical absorption process in the whole range of $x_{\mathrm{CO}_{2}}^{i}$. Clearly, hybrid absorption is not preferred in this situation. For feed gases containing $35 \% \mathrm{CO}_{2}$ (see Figure 4b), the cost of hybrid absorption first decreases as $x_{\mathrm{CO}_{2}}^{i}$ increases from $1.5 \%$ to $3 \%$ and then increases as $x_{\mathrm{CO}_{2}}^{i}$ continues increasing to $5 \%$. Compared 
with physical and chemical absorption, the hybrid absorption process can lead to a maximal reduction of TAC by $0.7 \mathrm{M} \$ / y e a r$ and $3.1 \mathrm{M} \$ / y e a r$, respectively. Therefore in this case, hybrid absorption with an intermediate $\mathrm{CO}_{2}$ concentration of $3 \%$ should be employed. Finally, as shown in Figure 4c, when $x_{\mathrm{CO}_{2}}^{f}$ is $65 \%$, physical absorption results in the minimal TAC among all the absorption processes, which makes it most promising for capturing such a high concentration of $\mathrm{CO}_{2}$.

It can be concluded that the selection of the most economical absorption technology depends on the $\mathrm{CO}_{2}$ content in the feed gas. Additionally, when hybrid absorption is applied, its economic performance is also affected by the selection of $\mathrm{CO}_{2}$ content in the intermediate stream.

\subsubsection{Optimal selection of absorption processes}

Based on the above analysis on process $T A C$ for specific $\mathrm{CO}_{2}$ feed contents, we have acquired some preliminary knowledge on the selection of absorption processes. In order to obtain quantitative selection criteria, $x_{\mathrm{CO}_{2}}^{f}-\mathrm{TAC}$ relationship models are regressed based on the discrete TAC data listed in Table 3 using the following expressions. ${ }^{15}$

$T A C=\alpha+\beta \cdot\left(x_{\mathrm{CO}_{2}}^{f}\right)^{\gamma}$

$\alpha, \beta$, and $\gamma$ are fitting parameters. Table 4 shows the explicit TAC functions for all the process alternatives. Using these functions, a minimum $T A C$ profile for treating gases containing $9 \% \sim 76 \% \mathrm{CO}_{2}$ (lowest and highest $\mathrm{CO}_{2}$ contents in atmospheric-pressure industrial gases, see Table 1) can be obtained. As indicated in Figure 5, when $x_{\mathrm{CO}_{2}}^{f}$ is less than $30.4 \%$, chemical absorption is economically preferred. When $x_{\mathrm{CO}_{2}}^{f}$ falls into the range of [30.4\%, 59.3\%], hybrid 
absorption is most cost-effective and should be selected. Regarding the operation of the hybrid process, $3 \% \mathrm{CO}_{2}$ in the intermediate stream should be chosen when $30.4 \% \leq x_{\mathrm{CO}_{2}}^{f} \leq 35.3 \% ; 2 \%$ should be used if $35.3 \%<x_{\mathrm{CO}_{2}}^{f}<37.9 \%$; and $1.5 \%$ is preferred when $37.9 \% \leq x_{\mathrm{CO}_{2}}^{f} \leq 59.3 \%$. Finally, if $x_{\mathrm{CO}_{2}}^{f}$ is larger than $59.3 \%$, physical absorption shows the highest economic performance and thus should be used.

One should note that in industry the $\mathrm{CO}_{2}$ feed concentration $x_{\mathrm{CO}_{2}}^{f}$ can be time dependent. Typically, $x_{\mathrm{CO}_{2}}^{f}$ at time $t$ can be described by a probability distribution function and is constrained within a range $\left[L_{x_{\mathrm{CO}_{2}}^{f}}, U_{x_{\mathrm{CO}_{2}}^{f}}\right]$. For handling the impact of this $x_{\mathrm{CO}_{2}}^{f}$ uncertainty, the easiest way is to employ the worst-case scenario method where the worst case $U_{x_{\mathrm{CO}_{2}}^{f}}$ is set as the $\mathrm{CO}_{2}$ feed concentration in designing the absorption process. This ensures the separation target fulfilled for all the $x_{\mathrm{CO}_{2}}^{f}$ fluctuations.

\subsection{Scenario 2: High-pressure Pre-combustion Gas}

In Scenario 2, the pre-combustion gas (see Table 2) is considered as the feed gas. Similarly, the two carbon capture requirements in Equations (1) - (2) have to be fulfilled. After simulating the three absorption processes for treating this pre-combustion gas, the process $T A C$ are obtained and compared in Figure 6. As can be seen, the hybrid absorption process with an intermediate $\mathrm{CO}_{2}$ molar fraction of $2 \%$ results in the minimal cost. The corresponding TAC is $9.2 \mathrm{M} \$ /$ year, lower than those of the physical (9.6 M\$/year) and chemical (26.2 M\$/year) absorption processes. Thus, hybrid absorption should be employed for pre-combustion gas treatment. 


\section{Conclusion}

A comparative economic analysis on physical, chemical, and hybrid physical-chemical absorption processes is performed for capturing $\mathrm{CO}_{2}$ from various industrial gases with different compositions and pressures. It is found that for carbon capture at atmospheric pressure, chemical absorption is most economically-favorable when the $\mathrm{CO}_{2}$ concentration is lower than $30.4 \%$, hybrid absorption is cost-effective for medium $\mathrm{CO}_{2}$ compositions (30.4\% 59.3\%), and physical absorption should be applied when the $\mathrm{CO}_{2}$ content is higher than 59.3\%. For treating highpressure feed gases, the hybrid absorption process is always economically preferred. Even though no rigorous process optimization is considered, all the studied processes are designed and specified according to literature reports. ${ }^{11,20,27,28,30}$ From this perspective, the main conclusions drawn above are valuable and instructive for guiding the selection of absorption technologies for specific carbon capture tasks.

In this work, DEPG and MEA are fixed as the physical and chemical solvents, respectively due to their reported high performance. However, recently many efforts have been made to rationally design solvents for enhancing the absorption efficiency. ${ }^{27,33-35}$ The optimal solvent selection can improve the economic performance of the absorption process thus may influence the results of optimal process selection. On the other hand, as the other carbon capture technologies (e.g., adsorption ${ }^{36,37}$ and membrane separation ${ }^{38}$ ) become commercially competitive, they should be studied and compared with the absorption processes. Additionally, hybrid schemes that combine more than one separation technology (such as absorptionadsorption) are also worth studying for carbon capture applications. Taking into account the solvent effects and other $\mathrm{CO}_{2}$ capture methods can potentially help find more cost-effective 
solutions, and thus deserves further investigation in future work. Finally, as capturing $\mathrm{CO}_{2}$ is never the ultimate goal, to identify the best way of utilizing $\mathrm{CO}_{2}$ is always significant.

\section{Supporting Information}

The Supporting Information is available free of charge on the ACS Publications website at $* * * * * *$.

List of cost parameters for economic analysis; Detailed settings in Aspen Plus for physical, chemical, and hybrid absorption processes (doc) 


\section{Reference}

1. Global Energy and CO2 Status Report 2018; International Energy Agency: France, 2019.

2. Demirhan, C. D.; Tso, W. W.; Powell, J. B.; Pistikopoulos, E. N. Sustainable ammonia production through process synthesis and global optimization. AIChE J. 2019, 65 (7), e16498.

3. Miller, D. C.; Litynski, J. T.; Brickett, L. A.; Morreale, B. D. Toward transformational carbon capture systems. AIChE J. 2016, 62 (1), 2-10.

4. MacDowell, N.; Florin, N.; Buchard, A.; Hallett, J.; Galindo, A.; Jackson, G.; Adjiman, C. S.; Williams, C. K.; Shah, N.; Fennell, P. An overview of CO2 capture technologies. Energy Environ. Sci. 2010, 3 (11), 1645-1669.

5. Vooradi, R.; Anne, S. B.; Tula, A. K.; Eden, M. R.; Gani, R. Energy and CO2 management for chemical and related industries: issues, opportunities and challenges. BMC Chem. Eng. 2019, $1(1), 7$.

6. Zaman, M.; Lee, J. H. Carbon capture from stationary power generation sources: A review of the current status of the technologies. Korean J. Chem. Eng. 2013, 30 (8), 1497-1526.

7. Leung, D. Y. C.; Caramanna, G.; Maroto-Valer, M. M. An overview of current status of carbon dioxide capture and storage technologies. Renew. Sustain. Energy Rev. 2014, 39, 426443.

8. Bui, M.; Adjiman, C. S.; Bardow, A.; Anthony, E. J.; Boston, A.; Brown, S.; Fennell, P. S.; Fuss, S.; Galindo, A.; Hackett, L. A.; Hallett, J. P.; Herzog, H. J.; Jackson, G.; Kemper, J.; Krevor, S.; Maitland, G. C.; Matuszewski, M.; Metcalfe, I. S.; Petit, C.; Puxty, G.; Reimer, 
J.; Reiner, D. M.; Rubin, E. S.; Scott, S. A.; Shah, N.; Smit, B.; Trusler, J. P. M.; Webley, P.; Wilcox, J.; Mac Dowell, N. Carbon capture and storage (CCS): the way forward. Energy Environ. Sci. 2018, 11 (5), 1062-1176.

9. Bhattacharyya, D.; Miller, D. C. Post-combustion CO2 capture technologies - a review of processes for solvent-based and sorbent-based CO2 capture. Curr. Opin. Chem. Eng. 2017, $17,78-92$.

10. Liang, Z. H.; Sanpasertparnich, T.; Tontiwachwuthikul, P. P. T.; Gelowitz, D.; Idem, R. Part 1: Design, modeling and simulation of post-combustion $\mathrm{CO} 2$ capture systems using reactive solvents. Carbon Manag. 2011, 2 (3), 265-288.

11. Lampert, K.; Ziebik, A. Comparative analysis of energy requirements of CO2 removal from metallurgical fuel gases. Energy 2007, 32 (4), 521-527.

12. Mumford, K. A.; Wu, Y.; Smith, K. H.; Stevens, G. W. Review of solvent based carbondioxide capture technologies. Front. Chem. Sci. Eng. 2015, 9 (2), 125-141.

13. Olajire, A. A. CO2 capture and separation technologies for end-of-pipe applications - A review. Energy 2010, 35 (6), 2610-2628.

14. Yuan, Z.; Eden, M. R.; Gani, R. Toward the development and deployment of large-scale carbon dioxide capture and conversion processes. Ind. Eng. Chem. Res. 2016, 55 (12), 33833419.

15. Hasan, M. M. F.; Baliban, R. C.; Elia, J. A.; Floudas, C. A. Modeling, simulation, and optimization of postcombustion $\mathrm{CO} 2$ capture for variable feed concentration and flow rate. 1. chemical absorption and membrane processes. Ind. Eng. Chem. Res. 2012, 51 (48), 1564215664. 
16. Bains, P.; Psarras, P.; Wilcox, J. CO2 capture from the industry sector. Prog. Energy Combust. Sci. 2017, 63, 146-172.

17. Voldsund, M.; Jordal, K.; Anantharaman, R. Hydrogen production with CO2 capture. Int. J. Hydrogen Energy 2016, 41 (9), 4969-4992.

18. Wilcox, J.; Haghpanah, R.; Rupp, E. C.; He, J.; Lee, K. Advancing adsorption and membrane separation processes for the gigaton carbon capture challenge. Annu. Rev. Chem. Biomol. Eng. 2014, 5 (1), 479-505.

19. Husebye, J.; Brunsvold, A. L.; Roussanaly, S.; Zhang, X. Techno economic evaluation of amine based $\mathrm{CO} 2$ capture: Impact of $\mathrm{CO} 2$ concentration and steam supply. Energy Procedia 2012, 23, 381-390.

20. Huang, W.; Zheng, D.; Xie, H.; Li, Y.; Wu, W. Hybrid physical-chemical absorption process for carbon capture with strategy of high-pressure absorption/medium-pressure desorption. Appl. Energy 2019, 239, 928-937.

21. Liu, X.; Huang, Y.; Zhao, Y.; Gani, R.; Zhang, X.; Zhang, S. Ionic liquid design and process simulation for decarbonization of shale gas. Ind. Eng. Chem. Res. 2016, 55 (20), 5931-5944.

22. Song, C.; Liu, Q.; Ji, N.; Deng, S.; Zhao, J.; Li, Y.; Song, Y.; Li, H. Alternative pathways for efficient $\mathrm{CO} 2$ capture by hybrid processes - A review. Renew. Sustain. Energy Rev. 2018, $82,215-231$.

23. Tula, A. K.; Befort, B.; Garg, N.; Camarda, K. V.; Gani, R. Sustainable process design \& analysis of hybrid separations. Comput. Chem. Eng. 2017, 105, 96-104. 
24. Roh, K.; Frauzem, R.; Nguyen, T. B.; Gani, R.; Lee, J. H. A methodology for the sustainable design and implementation strategy of $\mathrm{CO} 2$ utilization processes. Comput. Chem. Eng. 2016, $91,407-421$.

25. Roh, K.; Frauzem, R.; Gani, R.; Lee, J. H. Process systems engineering issues and applications towards reducing carbon dioxide emissions through conversion technologies. Chem. Eng. Res. Des. 2016, 116, 27-47.

26. Yue, D.; Gong, J.; You, F. Synergies between geological sequestration and microalgae biofixation for greenhouse gas abatement: Life cycle design of carbon capture, utilization, and storage supply chains. ACS Sustain. Chem. Eng. 2015, 3 (5), 841-861.

27. Im, D.; Roh, K.; Kim, J.; Eom, Y.; Lee, J. H. Economic assessment and optimization of the Selexol process with novel additives. Int. J. Greenhouse Gas Control 2015, 42, 109-116.

28. Kapetaki, Z.; Brandani, P.; Brandani, S.; Ahn, H. Process simulation of a dual-stage Selexol process for $95 \%$ carbon capture efficiency at an integrated gasification combined cycle power plant. Int. J. Greenhouse Gas Control 2015, 39, 17-26.

29. Zubeir, L. F.; Lacroix, M. H. M.; Meuldijk, J.; Kroon, M. C.; Kiss, A. A. Novel pressure and temperature swing processes for $\mathrm{CO} 2$ capture using low viscosity ionic liquids. Sep. Purif. Technol. 2018, 204, 314-327.

30. Rate-based Model of the CO2 Capture Process by MEA Using Aspen Plus. Aspen Technology Inc,: Cambridge, MA, 2008.

31. Aboudheir, A.; Tontiwachwuthikul, P.; Chakma, A.; Idem, R. Kinetics of the reactive absorption of carbon dioxide in high $\mathrm{CO} 2$-loaded, concentrated aqueous monoethanolamine solutions. Chem. Eng. Sci. 2003, 58 (23), 5195-5210. 
32. Xu, G.; Jin, H.; Yang, Y.; Xu, Y.; Lin, H.; Duan, L. A comprehensive techno-economic analysis method for power generation systems with CO2 capture. Int. J. Energy Res. 2010, $34(4), 321-332$.

33. Chen, F. F.; Huang, K.; Fan, J. P.; Tao, D. J. Chemical solvent in chemical solvent: A class of hybrid materials for effective capture of CO2. AIChE J. 2018, 64 (2), 632-639.

34. Zhong, N.; Liu, H.; Luo, X.; AL-Marri, M. J.; Benamor, A.; Idem, R.; Tontiwachwuthikul, P.; Liang, Z. Reaction kinetics of carbon dioxide (CO2) with diethylenetriamine and 1-amino-2propanol in nonaqueous solvents using stopped-flow technique. Ind. Eng. Chem. Res. 2016, 55 (27), 7307-7317.

35. Taheri, M.; Dai, C.; Lei, Z. CO2 capture by methanol, ionic liquid, and their binary mixtures: Experiments, modeling, and process simulation. AIChE J. 2018, 64 (6), 2168-2180.

36. Krishnamurthy, S.; Rao, V. R.; Guntuka, S.; Sharratt, P.; Haghpanah, R.; Rajendran, A.; Amanullah, M.; Karimi, I. A.; Farooq, S. CO2 capture from dry flue gas by vacuum swing adsorption: A pilot plant study. AIChE J. 2014, 60 (5), 1830-1842.

37. Agarwal, A.; Biegler, L. T.; Zitney, S. E. Superstructure-based optimal synthesis of pressure swing adsorption cycles for precombustion CO2 capture. Ind. Eng. Chem. Res. 2009, 49 (11), 5066-5079.

38. Ho, M. T.; Allinson, G. W.; Wiley, D. E. Reducing the cost of CO2 capture from flue gases using membrane technology. Ind. Eng. Chem. Res. 2008, 47 (5), 1562-1568. 


\section{Table Captions}

Table 1. Conditions of $\mathrm{CO}_{2}$-containing gases in different industrial sectors ${ }^{15-18}$

Table 2. Feed gas conditions considered in the two scenarios

Table 3. TAC (M\$/year) of the absorption processes for feed gases in Scenario 1

Table 4. Regressed $x_{\mathrm{CO}_{2}}^{f}-\mathrm{TAC}$ relationship models for different absorption processes (TAC in $\mathrm{M} \$ /$ year and $x_{\mathrm{CO}_{2}}^{f}$ in $\left.\%\right)$ 
Table 1. Conditions of $\mathrm{CO}_{2}$-containing gases in different industrial sectors ${ }^{15-18}$

\begin{tabular}{|c|c|c|c|c|c|c|}
\hline \multirow{2}{*}{$\mathrm{CO}_{2}$-containing gases ${ }^{*}$} & \multicolumn{5}{|c|}{ Molar fraction (\%) } & \multirow{2}{*}{$\begin{array}{l}\text { Pressure } \\
\quad \text { (bar) }\end{array}$} \\
\hline & $\mathrm{CO}_{2}$ & $\mathrm{~N}_{2}$ & $\mathrm{O}_{2}$ & $\mathrm{CO}$ & $\mathrm{H}_{2}$ & \\
\hline $\begin{array}{l}\text { Post-combustion flue gas from coal } \\
\text { or natural gas fired power plants }\end{array}$ & $9-16$ & $70-84$ & $3-14$ & - & - & \\
\hline Flue gas in cement industry & $14-33$ & $59-72$ & $8-14$ & - & - & \\
\hline Tail gas from hydrogen production & $15-44$ & $0-38$ & - & $0-3$ & $54-80$ & 1 \\
\hline Flue gas in iron and steel industries & $20-45$ & $2-56$ & - & $21-45$ & $3-20$ & \\
\hline Oxy-combustion flue gas & $55-76$ & $16-23$ & $5-26$ & - & - & \\
\hline Pre-combustion gas $\#$ & $30-45$ & $2-5$ & - & $0-5$ & $45-65$ & $20-80$ \\
\hline
\end{tabular}

*Assuming dehydrated $\quad$ \# After water-gas shift reaction 
Table 2. Feed gas conditions considered in the two scenarios

\begin{tabular}{|c|c|c|c|c|c|c|}
\hline \multirow{2}{*}{ Scenario } & \multicolumn{5}{|c|}{ Molar fraction (\%) } & \multirow{2}{*}{$\begin{array}{l}\text { Pressure } \\
\text { (bar) }\end{array}$} \\
\hline & $\mathrm{CO}_{2}$ & $\mathrm{~N}_{2}$ & $\mathrm{O}_{2}$ & $\mathrm{CO}$ & $\mathrm{H}_{2}$ & \\
\hline \multirow{6}{*}{ Scenario 1} & 15 & 75 & 10 & - & - & \multirow{6}{*}{1} \\
\hline & 25 & 12 & - & 45 & 18 & \\
\hline & 35 & 5 & - & 42 & 18 & \\
\hline & 45 & 10 & - & 25 & 20 & \\
\hline & 55 & 22 & 23 & - & - & \\
\hline & 65 & 17 & 18 & - & - & \\
\hline Scenario 2 & 35 & 5 & - & 5 & 55 & 30 \\
\hline
\end{tabular}


Table 3. TAC (M\$year) of the absorption processes for feed gases in Scenario 1

\begin{tabular}{|c|c|c|c|c|c|c|c|}
\hline \multirow{2}{*}{\multicolumn{2}{|c|}{ Processes }} & \multicolumn{6}{|c|}{$\mathrm{CO}_{2}$ molar fraction in the feed gas (\%), $x_{\mathrm{CO}_{2}}^{f}$} \\
\hline & & 15 & 25 & 35 & 45 & 55 & 65 \\
\hline \multicolumn{2}{|c|}{ Physical absorption } & 22.8 & 23.3 & 23.8 & 24.2 & 24.6 & 25.1 \\
\hline \multicolumn{2}{|c|}{ Chemical absorption } & 11.3 & 18.3 & 26.2 & 33.8 & 41.9 & 48.5 \\
\hline \multirow{5}{*}{$\begin{array}{c}\text { Hybrid } \\
\text { absorption } \\
\text { with different } \\
x_{\mathrm{CO}_{2}}^{i}(\%)\end{array}$} & 1.5 & 22.5 & 23.0 & 23.3 & 23.7 & 24.4 & 25.3 \\
\hline & 2.0 & 21.8 & 22.7 & 23.2 & 23.6 & 24.5 & 25.4 \\
\hline & 3.0 & 21.1 & 22.5 & 23.1 & 23.8 & 24.7 & 25.6 \\
\hline & 4.0 & 20.8 & 22.5 & 23.3 & 24.1 & 24.9 & 25.7 \\
\hline & 5.0 & 20.7 & 22.6 & 23.6 & 24.4 & 25.0 & 25.8 \\
\hline
\end{tabular}


Table 4. Regressed $x_{\mathrm{CO}_{2}}^{f}-\mathrm{TAC}$ relationship models for different absorption processes (TAC in $\mathrm{M} \$ /$ year and $x_{\mathrm{CO}_{2}}^{f}$ in $\left.\%\right)$

\begin{tabular}{|c|c|c|}
\hline \multicolumn{2}{|c|}{ Processes } & $x_{\mathrm{CO}_{2}}^{f}-T A C$ relationship models \\
\hline \multicolumn{2}{|c|}{ Physical absorption } & $T A C=21.81+0.12 \cdot\left(x_{\mathrm{CO}_{2}}^{f}\right)^{0.80}$ \\
\hline \multicolumn{2}{|c|}{ Chemical absorption } & $T A C=-0.46+0.79 \cdot\left(x_{\mathrm{CO}_{2}}^{f}\right)^{0.99}$ \\
\hline \multirow{5}{*}{$\begin{array}{c}\text { Hybrid } \\
\text { absorption } \\
\text { with different } \\
x_{\mathrm{CO}_{2}}^{i}(\%)\end{array}$} & 1.5 & $T A C=22.54+0.00024 \cdot\left(x_{\mathrm{CO}_{2}}^{f}\right)^{2.24}$ \\
\hline & 2.0 & $T A C=21.41+0.014 \cdot\left(x_{\mathrm{CO}_{2}}^{f}\right)^{1.36}$ \\
\hline & 3.0 & $T A C=18.71+0.41 \cdot\left(x_{\mathrm{CO}_{2}}^{f}\right)^{0.67}$ \\
\hline & 4.0 & $T A C=11.84+4.23 \cdot\left(x_{\mathrm{CO}_{2}}^{f}\right)^{0.28}$ \\
\hline & 5.0 & $T A C=-865.58+877.33 \cdot\left(x_{\mathrm{CO}_{2}}^{f}\right)^{0.0038}$ \\
\hline
\end{tabular}




\section{Figure Captions}

Figure 1. Flowsheets of DEPG-based physical absorption process (a), MEA-based chemical absorption process (b), and hybrid physical-chemical absorption process (c).

Figure 2. TAC of the physical and chemical absorption processes for feed gases in Scenario 1

Figure 3. Cost breakdown of the physical (a) and chemical (b) absorption processes for feed gases with $15 \%, 35 \%$, and $65 \% \mathrm{CO}_{2}$ at atmospheric pressure

Figure 4. Cost comparison of the absorption processes for feed gases with $15 \% \mathrm{CO}_{2}$ (a), $35 \%$ $\mathrm{CO}_{2}(\mathrm{~b})$, and $65 \% \mathrm{CO}_{2}(\mathrm{c})$ at atmospheric pressure

Figure 5. Minimal process TAC for treating gases containing 9\% $\sim 76 \% \mathrm{CO}_{2}$ at atmospheric pressure using different absorption technologies

Figure 6. Cost comparison of the absorption processes for pre-combustion gas (Scenario 2) treatment 


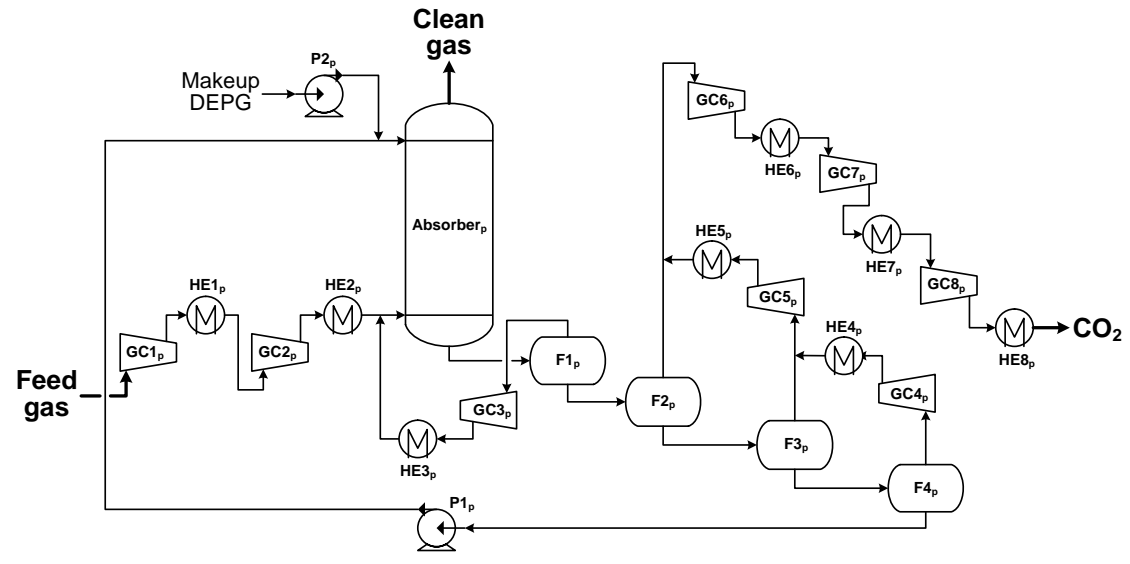

(a)

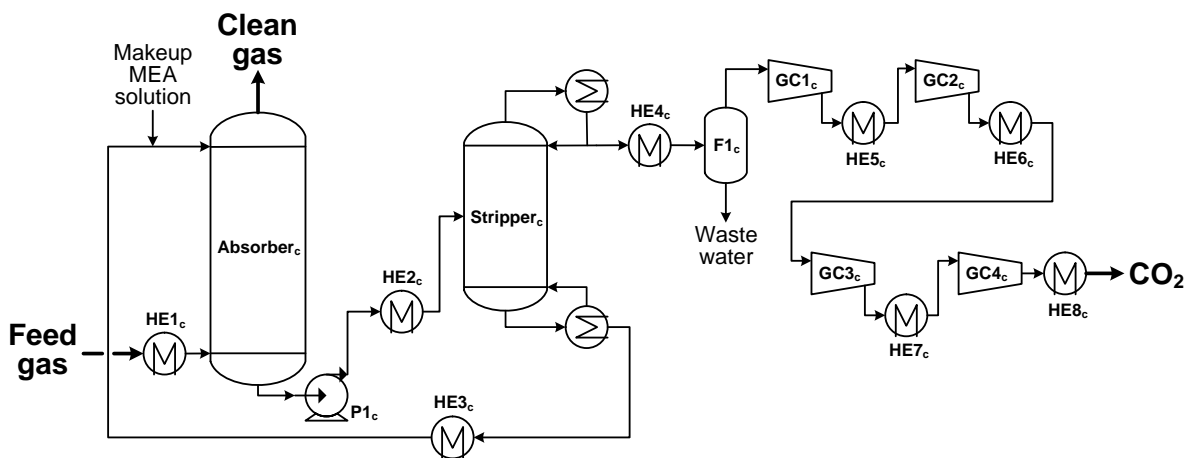

(b)

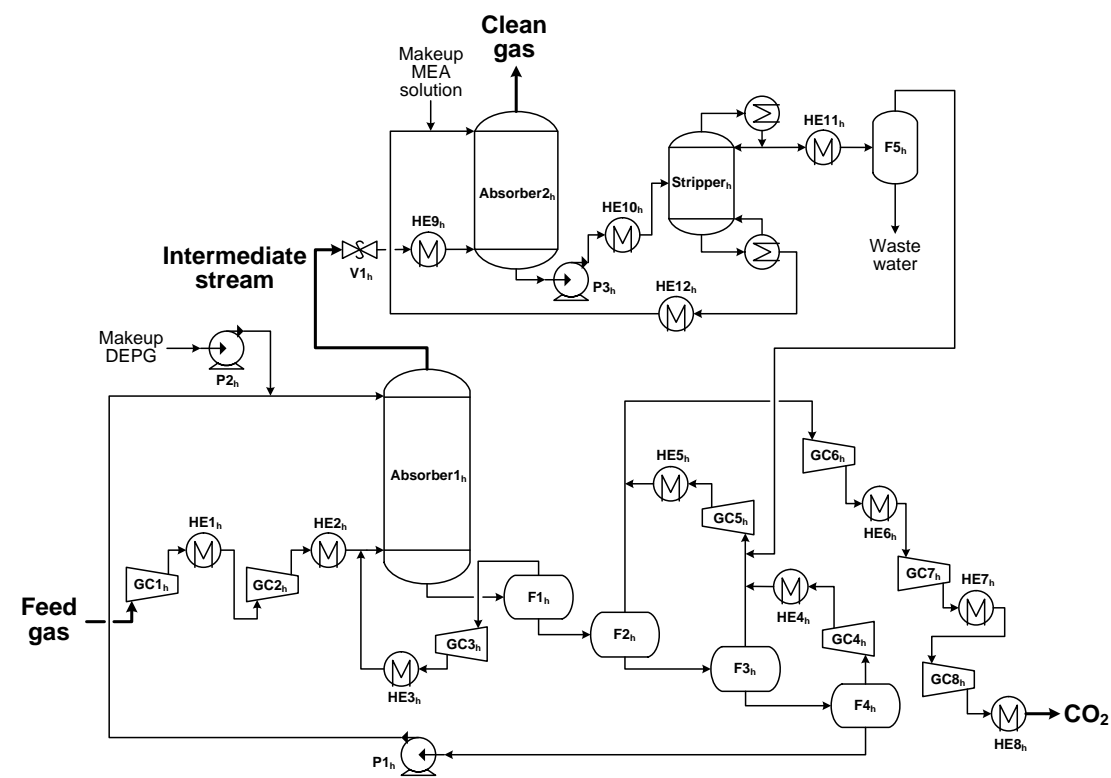

(c)

Figure 1. Flowsheets of DEPG-based physical absorption process (a), MEA-based chemical absorption process (b), and hybrid physical-chemical absorption process (c). 


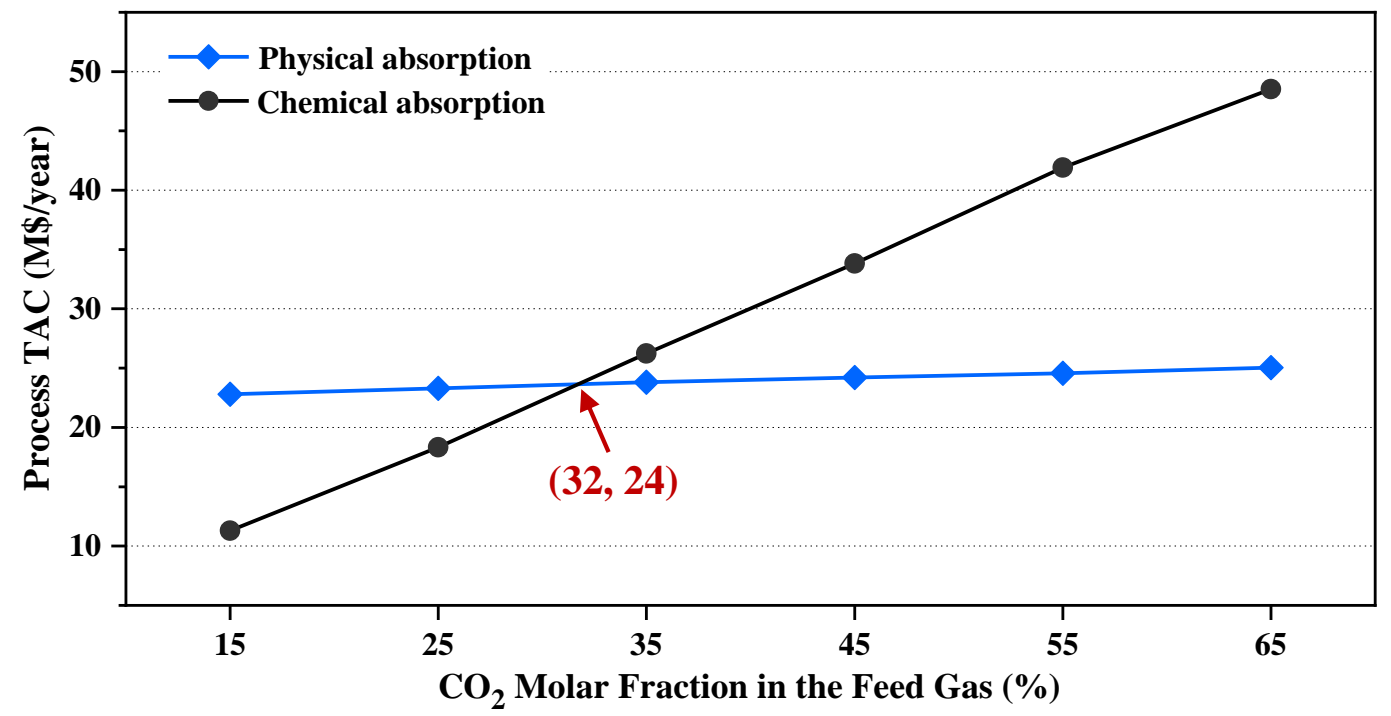

Figure 2. TAC of the physical and chemical absorption processes for feed gases in Scenario 1 


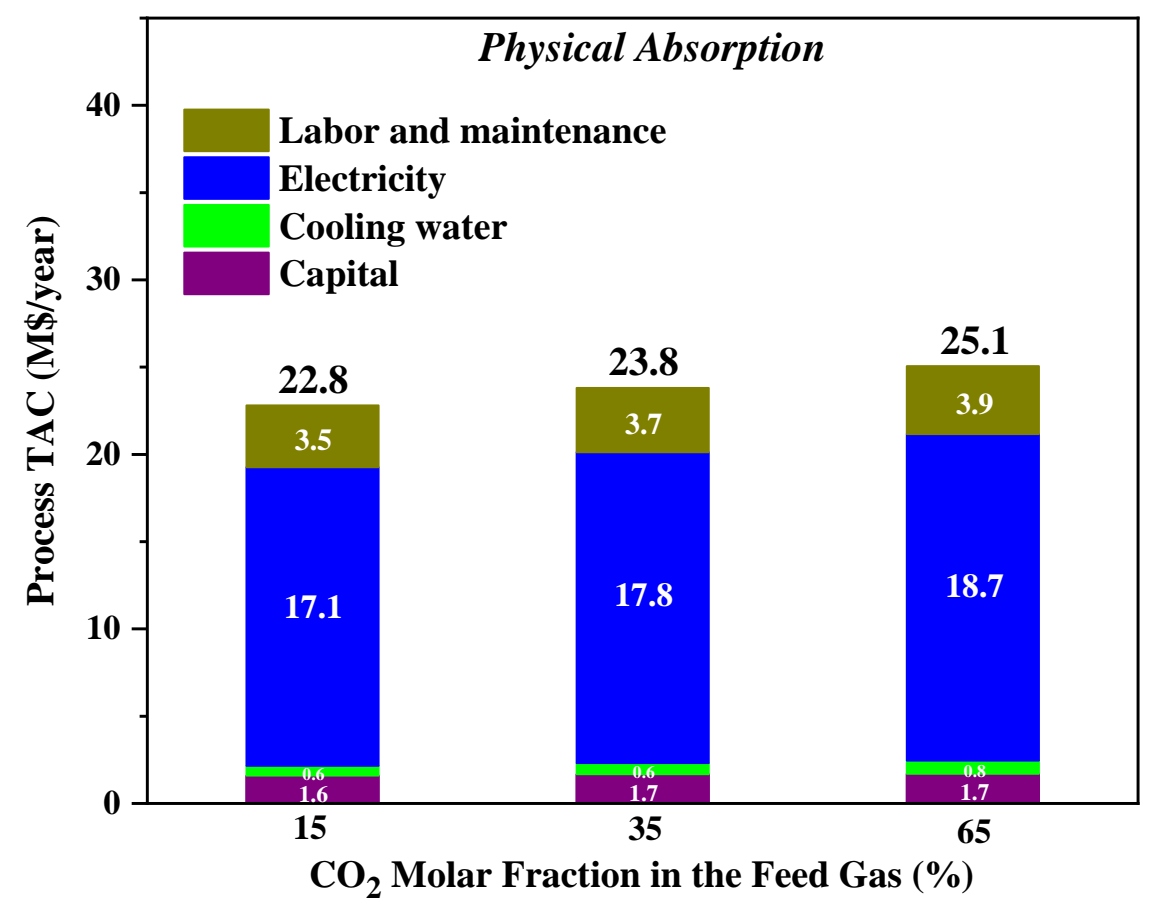

(a)

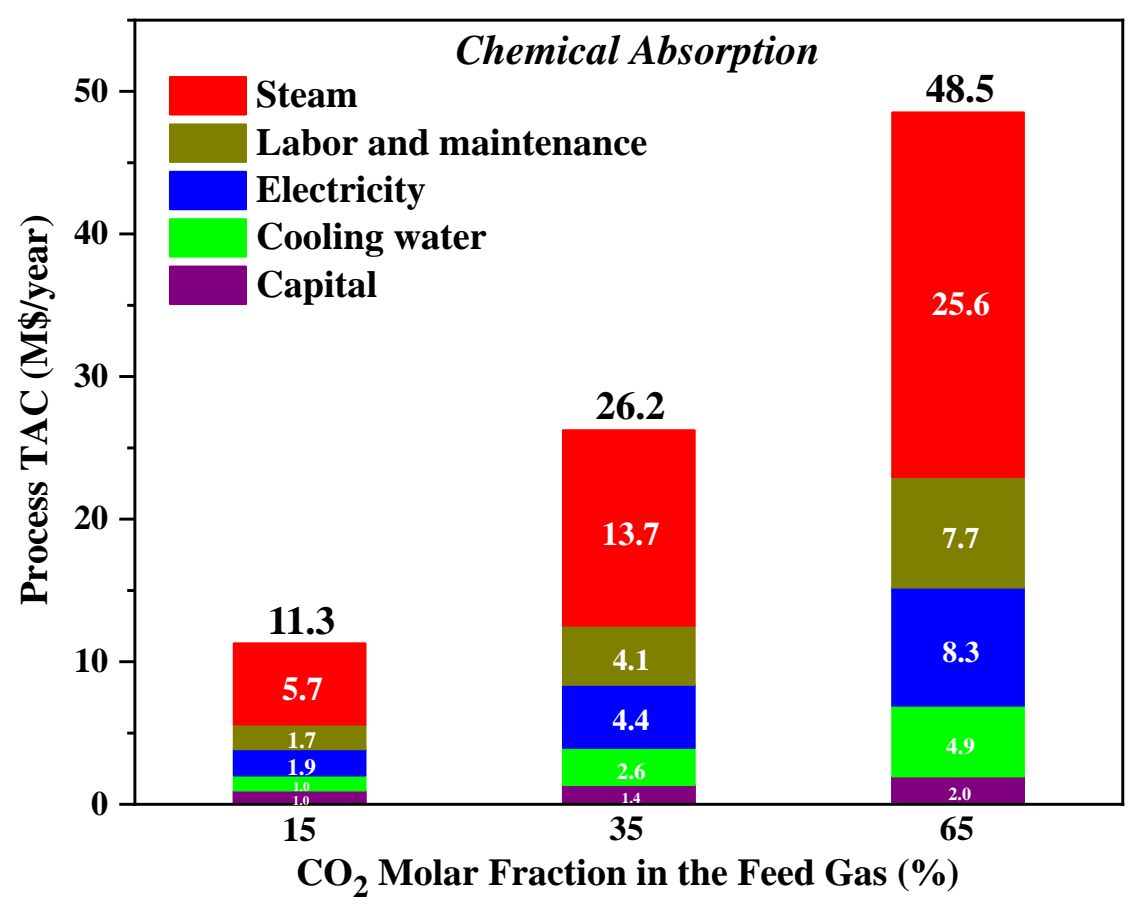

(b)

Figure 3. Cost breakdown of the physical (a) and chemical (b) absorption processes for feed gases with $15 \%, 35 \%$, and $65 \% \mathrm{CO}_{2}$ at atmospheric pressure 


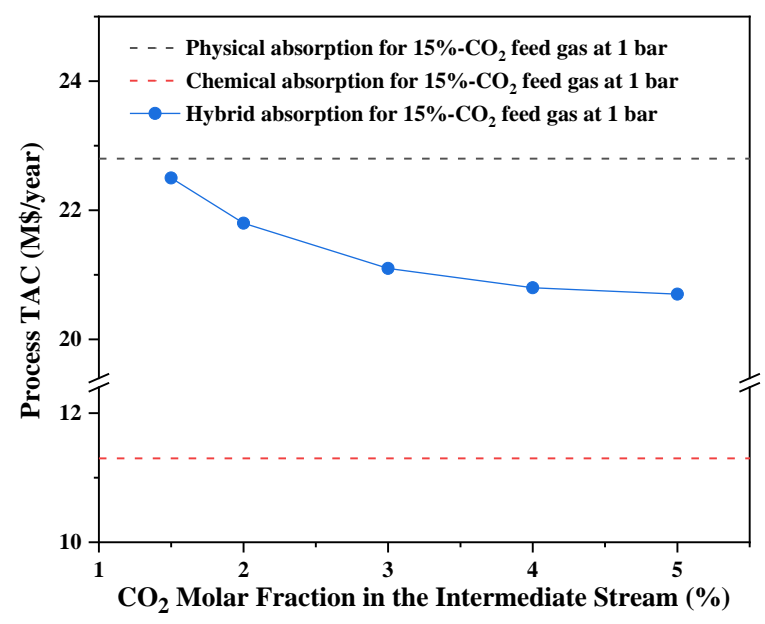

(a)

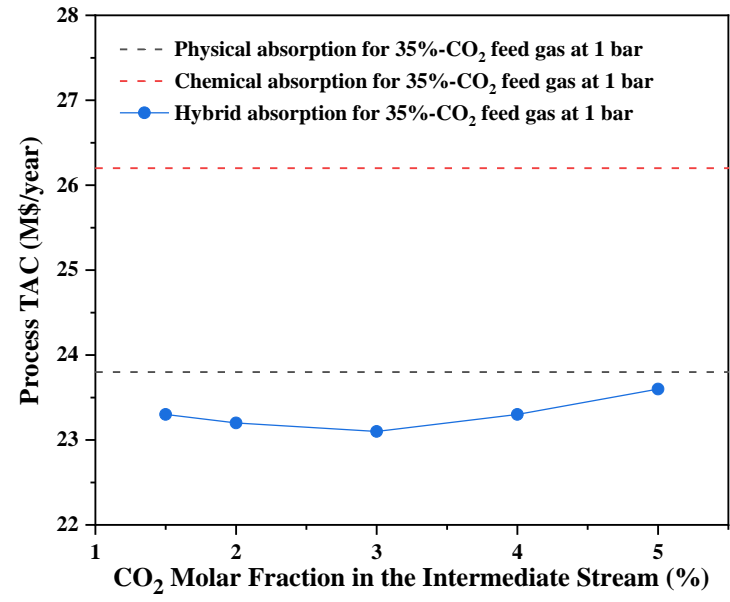

(b)

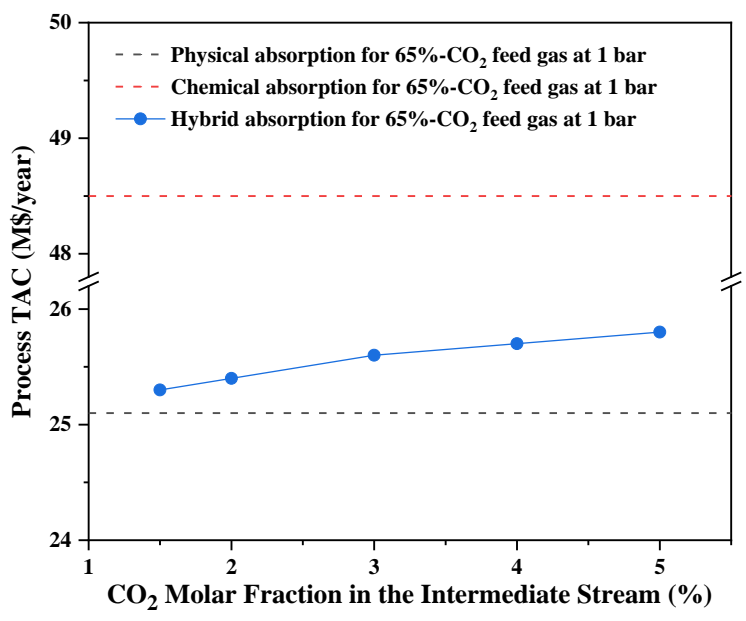

(c)

Figure 4. Cost comparison of the absorption processes for feed gases with $15 \% \mathrm{CO}_{2}$ (a), $35 \%$ $\mathrm{CO}_{2}(\mathrm{~b})$, and $65 \% \mathrm{CO}_{2}$ (c) at atmospheric pressure 


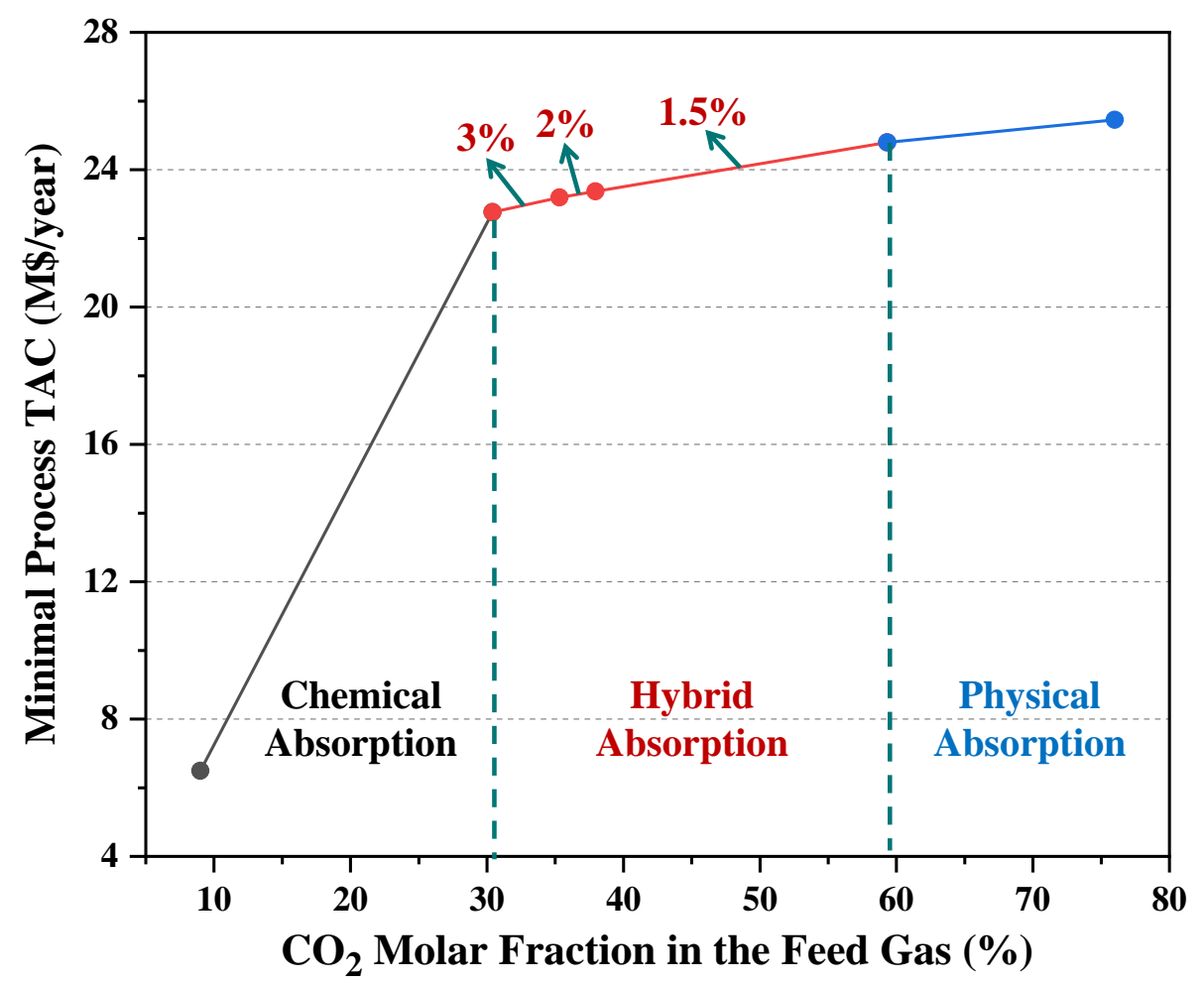

Figure 5. Minimal process TAC for treating gases containing 9\% 76\% $\mathrm{CO}_{2}$ at atmospheric pressure using different absorption technologies 


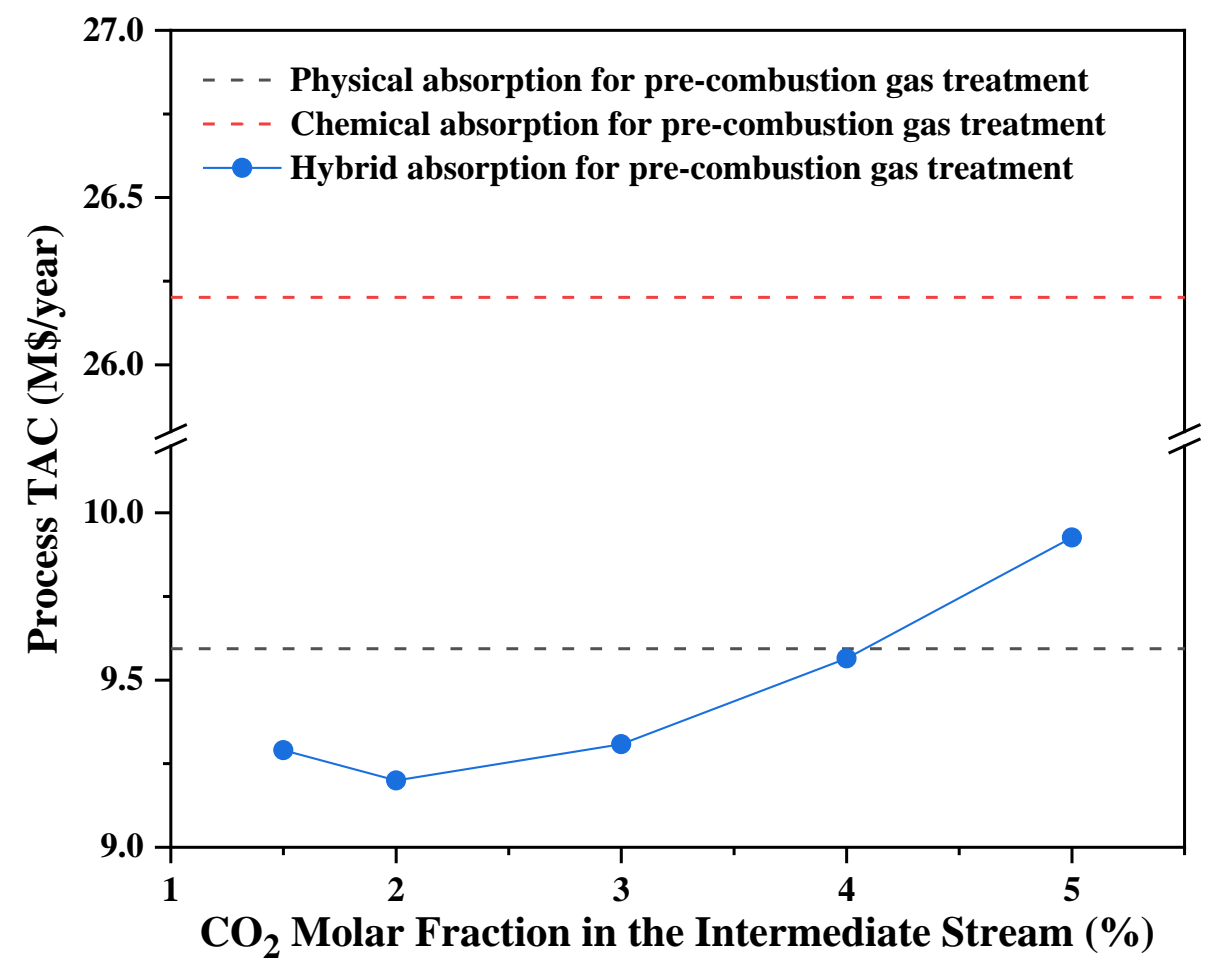

Figure 6. Cost comparison of the absorption processes for pre-combustion gas (Scenario 2) treatment 
Table of Contents (TOC) / Graphic Abstract

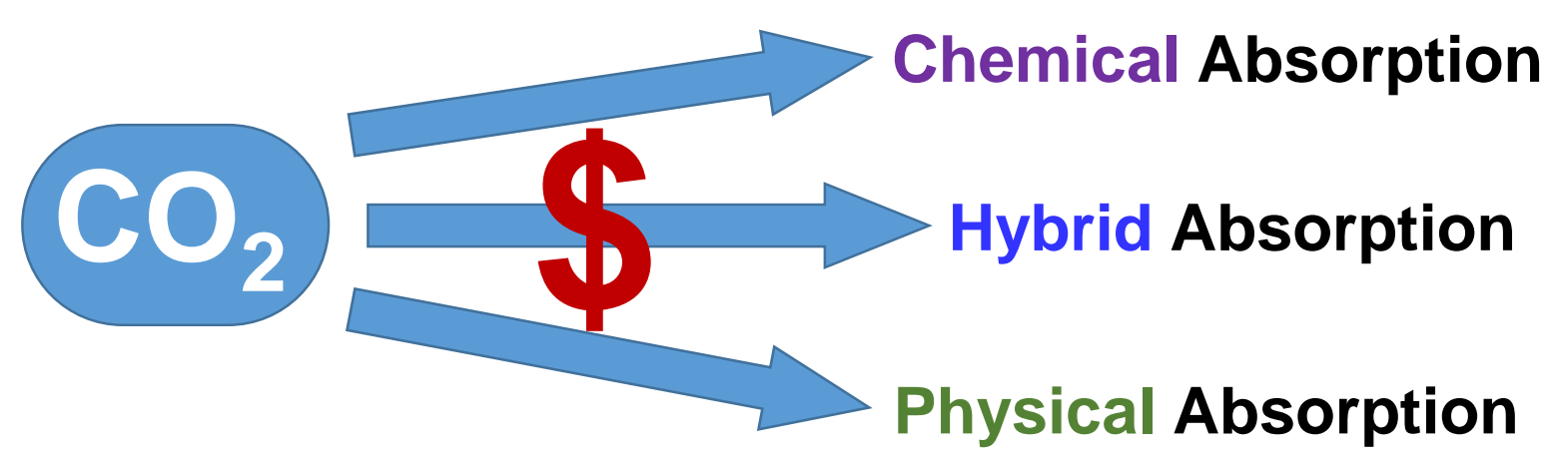

